\title{
Identification and characterization of ectoine-producing bacteria isolated from Can Gio mangrove soil in Vietnam
}

\author{
Doan Van Thuoc ${ }^{1}$ (D) Tran Thi Hien ${ }^{1} \cdot$ Kumar Sudesh ${ }^{2}$ \\ Received: 30 January 2019 / Accepted: 12 April 2019 / Published online: 26 April 2019 \\ (C) Università degli studi di Milano 2019
}

\begin{abstract}
Purpose The aim of this study was to characterize high ectoine-producing bacteria obtained from Can Gio mangrove soil samples in Vietnam.

Methods Ectoine-producing bacteria were isolated from mangrove soil samples. The selected strains were identified using 16S rDNA sequence analysis, and their biochemical characteristics were also examined. The ability to produce ectoine at different $\mathrm{NaCl}$ concentrations and the effect of osmotic downshock solution on ectoine's release rates and survival rates for the selected bacterial strains were investigated.

Results Among more than 200 bacterial colonies isolated from soil samples, two strains exhibiting highest ectoine production (strains D227 and D228) were chosen for further studies. Both strains D227 and D228 were identified as Halomonas spp. and were closely related to Halomonas organivorans, sharing 99.4\% $16 \mathrm{~S}$ rDNA sequence similarity. At $6 \%(w / v) ~ N a C l$ concentration, strains D227 and D228 presented the highest cell dry weight (CDW) of 3.85 and $3.55 \mathrm{~g} / \mathrm{l}$, respectively. At $18 \% \mathrm{NaCl}$ concentration, maximum total ectoine (ectoine and hydroxyectoine) production of 16.4 and $18.1 \mathrm{wt} \%$ was achieved by strains D227 and D228, respectively. After 30 min of incubation in downshock solution containing $5 \% \mathrm{NaCl}$, high bacterial survival rates of $96 \%$ and $98 \%$, and ectoines release rates of $61 \%$ and $76 \%$ were obtained by strains D227 and D228, respectively.

Conclusions The accumulation and secretion of ectoine appear to be a typical adaptation strategy of some bacteria to survive under the changing saline conditions of mangrove ecosystem. To the best of our knowledge, this is the first report on ectoine production by halophilic bacteria isolated from mangrove soil. High ectoine-producing bacteria can be found in mangrove forest.
\end{abstract}

Keywords Can Gio mangrove $\cdot$ Compatible solutes $\cdot$ Ectoine $\cdot$ Halomonas $\cdot$ Halophilic bacteria

\section{Introduction}

Many microorganisms synthesize and/or uptake compatible solutes for cell survival under stress conditions. Ectoine $(1,4,5,6-$ tetrahydro-2-methyl-4-pyrimidinecarboxylic acid) is one of the most abundant compatible solutes, intracellularly accumulated by many bacteria for protection from stress (Roberts 2005; Lentzen and Schwarz 2006), and has been receiving significant

Doan Van Thuoc

thuocdv@hnue.edu.vn

1 Department of Biotechnology and Microbiology, Faculty of Biology, Hanoi National University of Education, 136 Xuan Thuy, Cau Giay, Hanoi, Vietnam

2 School of Biological Sciences, Universiti Sains Malaysia, 11800 Penang, Malaysia attention because of its potential biotechnological applications (Pastor et al. 2010). It can be used as a protective agent for enzymes against stress conditions such as heat, cold, and high or low pH (Lippert and Galinski 1992; Van-Thuoc et al. 2013). It has been reported that addition of ectoine retained more than $80 \%$ of lactic dehydrogenase activity and $100 \%$ of phosphofructokinase activity after 4 cycles of freezing and thawing (Lippert and Galinski 1992). In addition, ectoine has also been shown to protect xylanase against $\mathrm{pH}$ stress; the enzyme completely lost its activity after $10 \mathrm{~h}$ of incubation at $\mathrm{pH} 4.5$, whereas, in the presence of ectoine, about $10 \%$ of the original activity was maintained at $\mathrm{pH} 4.5$ and significantly higher activity was noted at high $\mathrm{pH}$ of 11 and 12 (Van-Thuoc et al. 2013). Furthermore, ectoine can also be used for DNA protection. In a previous study, Schröter et al. (2017) reported that ectoine can prevent DNA strand breaks caused by ionizing electron radiation.

Besides its role in protecting macromolecules, many studies have also shown that ectoine can be used for whole cell 
protection. It has been demonstrated that the growth inhibition induced by osmotic stress in Escherichia coli can be reversed by the addition of ectoine into the culture medium (Malin and Lapidot 1996). Ectoine has also been found to protect human skin cells from the effects of harmful UV radiation (Bünger and Driller 2004). Kanapathipillai et al. (2004) showed that ectoine strongly inhibits $A \beta 42$ amyloid formation in vitro and reduces toxicity to human neuroblastoma cells, suggesting its potential role in treating Alzheimer's disease. Moreover, a recent clinical trial confirmed that ectoine-containing products reduced nasal and ocular symptoms in allergic rhinitis patients (Werkhäuser et al. 2014). Most of the high ectoine producers belong to the genus Halomonas. For instance, Halomonas elongata is currently used for large-scale production of ectoine (Kunte et al. 2014), Halomonas salina can secrete high quantities of ectoine into the culture medium at low salt concentration (Zhang et al. 2009), and Halomonas boliviensis can accumulate nearly $28 \%$ ectoines (ectoine and hydroxyectoine) in the cells during two-step fed-batch fermentation (Van-Thuoc et al. 2010).

Can Gio is one of the 24 districts of Ho Chi Minh City, Vietnam. Its total area is about 72,000 ha, with a land cover of 40,000 ha, and mangrove cover of 32,000 ha. The Can Gio mangrove forest covers the delta of Saigon, Dong Nai, and Vam Co Rivers. In January 2000, Can Gio was designated as the first Mangrove Biosphere Reserve in Vietnam under the Man and Biosphere Programme of the United Nations Education, Scientific, and Cultural Organization. In general, the soil water salinity in mangrove forests is dynamic and depends on the fresh water input. In the Can Gio mangrove forest, water salinity is high during dry season, reaching peaks of 2.5-3\% in March and April, but decreases during the rainy season to only $0.5-1 \%$ (Tuan and Kuenzer 2012; CostaBöddeker et al. 2017). Many different microorganisms, including bacteria, fungi, protozoa, and algae, have been found in mangrove ecosystems (Holguin et al. 2001; Van-Thuoc et al. 2012). To survive under dynamic water salinity, microorganisms may accumulate compatible solutes such as ectoine for maintaining osmotic balance. In the present study, production of ectoine by bacterial species isolated from Can Gio mangrove soil was investigated.

\section{Materials and methods}

\section{Samples collection and isolation of bacterial strains}

Soil samples were collected from the surface of the Can Gio mangrove forest in Southern Vietnam. The samples were immediately placed in a sealed container and transported to the laboratory. A total of $1 \mathrm{~g}$ of soil sample was inoculated into meat peptone agar (MPA) medium containing (g/l) peptone, 5; meat extract, 5 ; and $\mathrm{NaCl}, 150$. After 5 days of cultivation on a rotary shaker at $30^{\circ} \mathrm{C}$ and $180 \mathrm{rpm}, 1 \mathrm{ml}$ of the culture broth was serially diluted with $15 \% \mathrm{NaCl}$ solution, and $100 \mu \mathrm{l}$ of the diluted culture broth were spread onto MPA plates. The plates were incubated at $30^{\circ} \mathrm{C}$ for 5 days. More than 200 colonies were isolated and re-inoculated onto fresh MPA plates to obtain pure cultures.

\section{Screening of ectoine-producing bacterial strains}

Bacterial isolates were grown on MPA plates containing varying $\mathrm{NaCl}$ concentrations ranging from 3 to $21 \%$ at an increment of $3 \%(w / v)$. After $48 \mathrm{~h}$ of incubation, the bacterial strains that grew well in a wide range of salt concentrations were selected. The selected bacterial strains were then grown in MPA medium containing $15 \% \mathrm{NaCl}$ on a rotary shaker at $30{ }^{\circ} \mathrm{C}$ and $180 \mathrm{rpm}$. After $30 \mathrm{~h}$ of cultivation, samples were collected for cell dry weight (CDW) and ectoine analysis.

\section{Phylogenetic characterization of the selected ectoine-producing bacteria}

The genomic DNA of the selected strains was extracted by a Thermo Scientific GeneJET Genomic DNA Purification Kit according to the manufacturer's recommendations. The $16 \mathrm{~S}$ rDNA gene was amplified using the universal primers, $27 \mathrm{~F}$ (5'-AGAGTTTGATCCTGGCTCAG-3') and 1492R (5'GGTTACCTTGTTACGCTT-3'). Amplification was performed with the following PCR conditions, initial denaturation at $94{ }^{\circ} \mathrm{C}$ for $3 \mathrm{~min}, 30$ cycles of $94{ }^{\circ} \mathrm{C}$ for $30 \mathrm{~s}, 52{ }^{\circ} \mathrm{C}$ for $30 \mathrm{~s}$, and $72{ }^{\circ} \mathrm{C}$ for $1.5 \mathrm{~min}$, followed by a final extension at $72{ }^{\circ} \mathrm{C}$ for $7 \mathrm{~min}$. Sequencing of the amplified DNA fragment was performed at 1st Base (Singapore), and GenBank database was used to search for $16 \mathrm{~S}$ rDNA similarities. Phylogenic analysis based on 16S rDNA was performed with the aid of MEGA6 software (Tamura et al. 2013) using the neighbor-joining distance correlation method. The almost complete sequences (about $1400 \mathrm{bp}$ ) of the 16S rDNA genes of the strains isolated from the Can Gio mangrove forest were deposited in GenBank/EMBL/DDBJ databases (Accession numbers for strain D227 is MH715408 and strain D228 is MH715409) and used in the analysis.

\section{Morphological characteristics}

The shape and size of the selected bacterial strains were determined by scanning electron microscopy (SEM). After 24-h cultivation in liquid medium, the bacterial cells were collected by centrifugation, washed thrice with $0.1-\mathrm{M}$ phosphatebuffered saline, and fixed with $2.5 \%$ glutaraldehyde for $6 \mathrm{~h}$ and $1 \%$ osmic acid solution for $6 \mathrm{~h}$. The samples were dehydrated in 50\%, 70\%, 85\%, 95\%, and $100 \%$ ethanol solution. Subsequently, ethanol was replaced with isoamyl acetate, and the samples were dried with carbon dioxide. Lastly, the 
samples were sputter-coated with gold for 2 min and examined by SEM (S-4800, Hitachi, Japan).

\section{Biochemical tests}

The biochemical properties of the selected bacterial strains were determined using an ID 32 E kit (BioMérieux), which is a standardized system for the identification of Enterobacteriaceae and other non-fastidious Gram-negative rods. The kit comprises 32 miniaturized biochemical tests and a specific database.

\section{Effects of salt concentration on growth and ectoine accumulation of the selected strains}

The selected strains were grown in modified liquid HM (Medium for Halophile) containing (g/l): $\mathrm{MgSO}_{4} \cdot 7 \mathrm{H}_{2} \mathrm{O}, 0.5$; $\mathrm{CaCl}_{2} \cdot 2 \mathrm{H}_{2} \mathrm{O}, 0.009 ; \mathrm{KCl}, 0.05 ; \mathrm{K}_{2} \mathrm{HPO}_{4}, 0.5 ; \mathrm{FeSO}_{4} \cdot 7 \mathrm{H}_{2} \mathrm{O}$, 0.005; monosodium glutamate, 2; glucose, 10; and different $\mathrm{NaCl}$ concentrations, $0 \%, 2 \%, 3 \%, 4 \%, 5 \%, 6 \%, 7 \%, 8 \%$, $9 \%, 12 \%, 15 \%$, and $18 \%$. After $30 \mathrm{~h}$ of cultivation at $30{ }^{\circ} \mathrm{C}$ and $180 \mathrm{rpm}$, the bacterial cells were collected by centrifugation for CDW and ectoine analysis.

\section{Ectoine production in two-step fermentation}

The selected bacteria were first grown in $75 \mathrm{ml}$ of MPA medium containing $6 \% \mathrm{NaCl}$ in 250-ml Erlenmeyer flasks on a rotary shaker at $30{ }^{\circ} \mathrm{C}$ and $180 \mathrm{rpm}$ for $15 \mathrm{~h}$. The bacterial cells were harvested from the culture broth by centrifugation at $5000 \times \mathrm{g}$ for $10 \mathrm{~min}$ and then suspended in $75 \mathrm{ml}$ of $\mathrm{HM}$ with varying concentrations of $\mathrm{NaCl}(18 \%, 21 \%, 24 \%$, and $27 \%)$ in 250-ml Erlenmeyer flasks for ectoine production. After $24 \mathrm{~h}$ of cultivation, the bacterial cells were collected by centrifugation for CDW and ectoine analysis.

\section{Determination of ectoine release and bacterial cell survival after osmotic downshock}

The selected bacterial strains were grown in MPA medium containing $6 \% \mathrm{NaCl}$ at $30{ }^{\circ} \mathrm{C}$ and $180 \mathrm{rpm}$ for $15 \mathrm{~h}$ and then collected from the culture broth by centrifugation at $5000 \times \mathrm{g}$ for $10 \mathrm{~min}$. The pellet was suspended in fresh MPA medium containing $18 \% \mathrm{NaCl}$. After $24 \mathrm{~h}$ of cultivation, the cells were harvested by centrifugation and suspended in either distilled water or solutions containing $2.5 \%$ and $5 \% \mathrm{NaCl}$ for ectoine release. After $30 \mathrm{~min}$, the suspensions were centrifuged at $10,000 \times g$ for $10 \mathrm{~min}$. The supernatants containing released ectoine were analyzed by high-performance liquid chromatography (HPLC). The cell pellet obtained after centrifugation was suspended in $6 \% \mathrm{NaCl}$ solution, serially diluted with the same solution, and spread onto MPA plates containing $6 \%$ $\mathrm{NaCl}$. The bacterial cells obtained from the culture broth without being subjected to osmotic downshock were also serially diluted and spread onto MPA plates. The bacterial colonies on the plates were counted after $48 \mathrm{~h}$ of cultivation at $30{ }^{\circ} \mathrm{C}$. The percentage of cell survival was calculated based on the ratio of the number of colonies found after osmotic downshock and the number of colonies formed without osmotic downshock.

\section{Determination of CDW}

To determine the CDW of the selected bacterial strains, $3 \mathrm{ml}$ of the culture samples were centrifuged at $5000 \times \mathrm{g}$ for $15 \mathrm{~min}$ in a pre-weighed centrifuge tube, and the pellet was quickly washed with $3 \mathrm{ml}$ of distilled water, centrifuged, and dried at $105{ }^{\circ} \mathrm{C}$ until a constant weight was obtained. The centrifuge tube was weighed again to calculate the CDW.

\section{Ectoine analysis}

Extraction of ectoine was performed as reported previously (Kunte et al. 1993). In brief, $10 \mathrm{mg}$ of cell mass were extracted with $570 \mu \mathrm{l}$ of extraction mixture (methanol/chloroform/water, 10:5:4 v/v) by vigorous shaking for $5 \mathrm{~min}$, followed by addition of equal volumes $(170 \mu \mathrm{l})$ of chloroform and water. The mixture was shaken again for $10 \mathrm{~min}$ and phase separation was enhanced by centrifugation. The hydrophilic top layer containing compatible solutes was recovered, and the concentration of ectoine was determined by HPLC (Onraedt et al. 2005) using an UltiMate 3000 Standard Dual System with an Aminex HPX-87C column (Bio-Rad) and a UV detector at $65^{\circ} \mathrm{C}$. The compounds were monitored at $210 \mathrm{~nm}$, and calcium chloride $(5 \mathrm{mM})$ was used as a mobile phase at a flow rate of $0.3 \mathrm{ml} / \mathrm{min}$, with ectoine and hydroxyectoine (Sigma) employed as a standard for calibration. The intracellular ectoine content ( $\mathrm{g}$ ectoine per $\mathrm{g}$ biomass, percentage by weight - wt \%) and total ectoine concentration (ectoine per liter culture broth, g/l) were calculated according to standard procedures (Van-Thuoc et al. 2010).

\section{Results}

\section{Screening of ectoine-producing bacteria}

The pure cultures isolated from mangrove soil samples were grown on MPA plates containing different $\mathrm{NaCl}$ concentrations (from 3 to $21 \%$ ) at $30{ }^{\circ} \mathrm{C}$. After 24-h incubation, 12 bacterial strains that grew well in a wide range of salt concentrations were selected for further experiments. The selected strains were named D10, D16, D25, D30, D90, D91, D98, D209, D227, D228, D242, and D243. To test the ability of the selected strains to produce ectoine, the strains were grown in MPA medium containing $15 \% \mathrm{NaCl}$ at $30{ }^{\circ} \mathrm{C}$ for $30 \mathrm{~h}$. 
Then, the cells were harvested for CDW and ectoine analysis. As shown in Table 1, the 12 selected strains grew well in MPA medium. The highest CDW of $1.82 \mathrm{~g} / 1$ was exhibited by strain D98, whereas the lowest CDW of only $1.11 \mathrm{~g} / 1$ was presented by strain D90. Interestingly, all the selected strains could produce ectoine ranging from 2.2 to $9.9 \mathrm{wt} \%$. Among them, two strains, D227 and D228, accumulated the highest ectoine contents of 9.1 and $9.9 \mathrm{wt} \%$ respectively, and were selected for further analyses.

The phylogenetic characteristics of the two selected bacterial strains were analyzed using their 16S rDNA sequences. Strains D227 and D228 clustered together and presented a 16S rDNA sequence similarity of $100 \%$. The sequences of these strains shared a close relationship with those of Halomonas spp. and showed closest similarity with Halomonas organivorans (99.4\%), Halomonas koreensis (98.9\%), and Halomonas beimenensis (97.9\%) (Fig. 1).

\section{Phenotypic characterization of the selected strains}

The morphological and biochemical characteristics of the two selected strains are summarized in Table 2. The two selected strains were aerobic, Gram-negative, non-spore-forming, rodshaped, and occurred either singly or in pair (Fig. 2A, B). They were both moderately halophilic bacteria with optimum salt concentration of 5-6\% $(w / v)$. Besides, the strains were also mesophilic with optimum temperatures for growth between 30 and $35{ }^{\circ} \mathrm{C}$ and grew well at pH between 6 and 7 (Table 2). Moreover, both the strains were positive for catalase and indole tests, but were lipase- and urease-negative. The strains could utilize many of the tested compounds, including potassium 5-ketogluconate, 4-nitrophenyl- $\beta D$ glucopyranoside, D-mannitol, D-maltose, adonitol, palatinose, 4-nitrophenyl- $\beta \mathrm{D}$-galactopyranoside, D-glucose, sucrose, Larabinose, D-arabitol, 4-nitrophenyl- $\alpha \mathrm{D}$-glucopyranoside, 4-

Table 1 Bacterial growth and ectoine accumulation by 12 selected strains

\begin{tabular}{llll}
\hline Strain & $\begin{array}{l}\text { CDW } \\
(\mathrm{g} / \mathrm{l})\end{array}$ & $\begin{array}{l}\text { Ectoine } \\
\text { content }(\mathrm{wt} \%)\end{array}$ & $\begin{array}{l}\text { Ectoine conc. } \\
(\mathrm{g} / \mathrm{l})\end{array}$ \\
\hline $\mathrm{D} 10$ & 1.77 & 6.0 & 0.11 \\
$\mathrm{D} 16$ & 1.55 & 6.2 & 0.1 \\
$\mathrm{D} 25$ & 1.48 & 4.4 & 0.07 \\
$\mathrm{D} 30$ & 1.78 & 5.9 & 0.11 \\
$\mathrm{D} 90$ & 1.11 & 4.3 & 0.05 \\
$\mathrm{D} 91$ & 1.49 & 5.4 & 0.08 \\
$\mathrm{D} 98$ & 1.82 & 2.2 & 0.04 \\
$\mathrm{D} 209$ & 1.6 & 7.4 & 0.12 \\
$\mathrm{D} 227$ & 1.24 & 9.1 & 0.11 \\
$\mathrm{D} 228$ & 1.26 & 9.9 & 0.12 \\
$\mathrm{D} 242$ & 1.26 & 6.0 & 0.08 \\
$\mathrm{D} 243$ & 1.43 & 5.5 & 0.08 \\
\hline
\end{tabular}

nitrophenyl- $\alpha \mathrm{D}$-galactopyranoside, D-trehalose, L-rhamnose, inositol, D-cellobiose, D-sorbitol, and 4-nitrophenyl- $\alpha \mathrm{D}$ maltopyranoside. However, both the strains could not use Lornithine, L-arginine, L-lysine, L-arabitol, sodium pyruvate, 4nitrophenyl- $\beta \mathrm{D}$-glucuronide, 5-bromo-4-chloro-3-indolyl-Nacetyl- $\beta \mathrm{D}$-glucosaminide, and L-aspartic acid 4-nitroanilide. Although many of the characteristics of the two selected strains were obviously similar to those of $H$. organivorans CECT $5995^{\mathrm{T}}$, some features, such as the ability to use compounds, e.g. galacturonic acid, D-maltose, adonitol, L-tryptophan, and L-arabinose, were different between the two strains and H. organivorans (Table 2).

\section{Ectoine production by the selected strains at different $\mathrm{NaCl}$ concentrations}

Investigation of the effect of different $\mathrm{NaCl}$ concentrations on the growth and ectoine accumulation of the two strains isolated from the Can Gio mangrove forest showed that the strains were unable to grow in the absence of $\mathrm{NaCl}$. Salt concentrations between 4 and 7\% were optimal for the growth of the two isolates, and their growth rapidly decreased at $\mathrm{NaCl}$ concentrations higher than $9 \%$. Furthermore, at $6 \% \mathrm{NaCl}$ concentration, strains D227 and D228 presented maximum CDW of 3.85 and $3.55 \mathrm{~g} / 1$, respectively (Fig. 3). However, the optimal salt concentration for cell growth was not favorable for ectoine accumulation. Ectoine accumulation increased with the increasing $\mathrm{NaCl}$ concentration in the initial culture medium. At $15 \% \mathrm{NaCl}$ concentration, strains D227 and D228 exhibited highest ectoine production, reaching 11.26 and $14.07 \mathrm{wt} \%$, respectively (Fig. 3). Besides, although the two strains were found to grow at a higher $\mathrm{NaCl}$ concentration of $18 \%$, the obtained CDW was not sufficient for ectoine analysis.

Two-step fermentation was performed to investigate the effect of high concentration of $\mathrm{NaCl}$ on ectoine production by the two selected strains. After $15 \mathrm{~h}$ of growth in MPA medium containing $6 \% \mathrm{NaCl}$, the $\mathrm{CDW}$ of strains D227 and D228 reached 1.2 and $1.0 \mathrm{~g} / 1$ with ectoine contents of 4.6 and $4.9 \mathrm{wt} \%$, respectively (Fig. 4a-c). Subsequent incubation of the strains in $\mathrm{HM}$ containing $18 \%, 21 \%, 24 \%$, and $27 \% \mathrm{NaCl}$ revealed that the two strains could grow in the presence of $18 \%$ and $21 \% \mathrm{NaCl}$, but were destroyed at higher $\mathrm{NaCl}$ concentrations of $24 \%$ and $27 \%$. Maximum CDW of $2.3 \mathrm{~g} / \mathrm{l}$ was exhibited by strain D227 in the presence of $18 \% \mathrm{NaCl}$, which reduced to only $0.8 \mathrm{~g} / 1$ at $27 \% \mathrm{NaCl}$ concentration. Similar results were also noted for strain D228, with maximum CDW of $2.2 \mathrm{~g} / 1$ obtained at $18 \% \mathrm{NaCl}$ concentration, and only $0.5 \mathrm{~g} /$ $1 \mathrm{CDW}$ observed in the presence of $27 \% \mathrm{NaCl}$ (Fig. 4a). Maximum ectoine content of $16.5 \mathrm{wt} \%$ (14.5 wt\% ectoine and $2 \mathrm{wt} \%$ hydroxyectoine) was achieved by strain D227 in the presence of $18 \% \mathrm{NaCl}$, and the hydroxyectoine content slightly increased from 2 to $2.4 \mathrm{wt} \%$ when the $\mathrm{NaCl}$ concentration increased from 18 to $21 \%$. However, the ectoine 
Fig. 1 Phylogenetic tree constructed using $16 \mathrm{~S}$ rDNA gene sequences of the two selected strains belonging to the genus Halomonas. Bar, five subtitutions per 1000 nucleotides

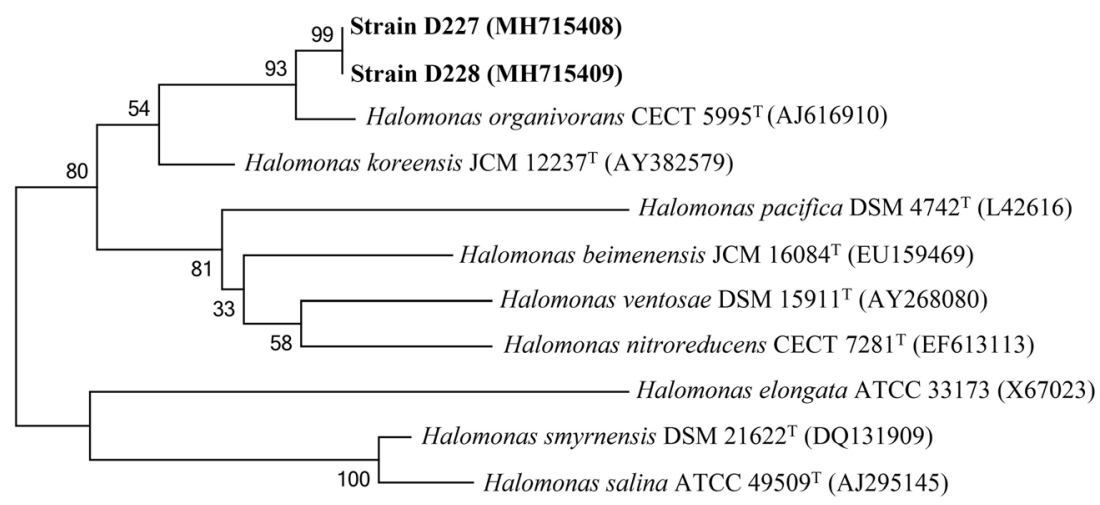

0.005 content decreased at higher salt concentrations and only a small amount of ectoine (3.9 wt\%) was detected in the presence of $27 \% \mathrm{NaCl}$ (Fig. 4b). As shown in Fig. 4c, maximum ectoine content of $18.1 \mathrm{wt} \%$ (14.6 and $3.5 \mathrm{wt} \%$ ectoine and hydroxyectoine content, respectively) was achieved by strain D228 at $18 \% \mathrm{NaCl}$ concentration. However, the total ectoine content dropped at higher salt concentrations and only ectoine was detected in the presence of $27 \% \mathrm{NaCl}$.

\section{Effect of osmotic downshock on ectoine release rates and bacterial survival rates}

The effect of osmotic downshock solutions containing different $\mathrm{NaCl}$ concentrations $(0 \%, 2.5 \%$, and $5 \%)$ on the amount of released ectoines and survival of the two selected bacterial strains was investigated. As shown in Fig. 5a, about $87 \%$ and $92 \%$ ectoines were released by strains D227 and D228, respectively, after 30 min when the bacterial cells (cultured in MPA medium containing $18 \% \mathrm{NaCl}$ ) were suspended in distilled water. The amount of released ectoines diminished to $64 \%$ and $61 \%$ for strain D227 and $86 \%$ and $76 \%$ for strain D228 when the $\mathrm{NaCl}$ concentration in the osmotic downshock solution was increased to $2.5 \%$ and $5 \%$, respectively. In contrast, the bacterial survival rates increased from 6 to $86 \%$ and $98 \%$ for strain D227 and from less than 1 to $34 \%$ and $96 \%$ for strain D228 when the $\mathrm{NaCl}$ concentration in the osmotic downshock solution was increased from 0 to $2.5 \%$ and $5 \%$, respectively (Fig. 5B).

\section{Discussion}

Two main strategies, namely, the "salt-in" and "compatible solute" strategies, are employed by microorganisms to cope with high external salt concentrations in the ecosystem that they inhabit. Accumulation of compatible solutes for osmotic adaptation is a typical mechanism found in many halotolerant and halophilic microorganisms (Roberts 2005). Compatible solutes include sugars, polyols, phosphodiesters, glyceric acid derivatives, and amino acids and their respective derivatives, betaines, and ectoine (Roberts 2005; Lentzen and Schwarz 2006). Ectoine is currently produced by "bacterial milking" process (Sauer and Galinski 1998), which involves repetitive cycles of two main steps: bacterial cells are first grown in hyperosmotic medium to induce ectoine accumulation and then harvested and transferred to osmotic downshock solution to promote ectoine release. Hence, bacteria that can grow and accumulate high amount of ectoine at a wide range of salt concentrations have promising application in this process.

It has been reported that the salt concentration in the soil water of the Can Gio mangrove forest is constantly below 3\% (w/v) (Tuan and Kuenzer 2012; Costa-Böddeker et al. 2017). As a result, bacterial strains in the soil of mangrove forests are mainly halotolerant and moderately halophilic (Van-Thuoc et al. 2012). Hence, to find promising ectoine-producing bacteria, in the present study, soil samples collected from the Can Gio mangrove forest were incubated in MPA medium containing $15 \% \mathrm{NaCl}$ for 5 days, which allowed the growth of halophilic or high salttolerant bacteria only. Among more than 200 halophilic and halotolerant bacterial colonies isolated, 12 strains were selected, all of which were able to produce ectoine (Table 1). The results of the present study showed that ectoine synthesis is a typical adaptation strategy that helps the isolated bacteria to survive under saline conditions in the mangrove ecosystem, suggesting that high ectoine-producing bacteria can be found in mangrove forests. A few previous studies found ectoine synthesis genes in the genome of some bacterial strains isolated from Malaysia such as Microbulbifer sp. CCM-MM1 (Moh et al. 2017), Hahella sp. strain CCB-MM4 (Sam et al. 2018), and Streptomyces mangrovisoli MUSC $149^{\mathrm{T}}$ (Ser et al. 2018). However, there are no reports on the production of ectoine by bacteria isolated from mangrove forest.

Phylogenetic studies of the two selected ectoine-producing strains showed that they were the same species belonging to the genus Halomonas (Fig. 1). Halomonas is the biggest genus of the family Halomonadaceae, with more than 100 species reported so far (http://www.bacterio.net/halomonas.html). These bacteria are Gram-negative, motile, and rod-shaped and have been found in a wide variety of saline environments such as 
Table 2 Phenotypic characteristics of the two selected strains and the reference strain $H$. organivorans (data obtained from García et al. 2004)

\begin{tabular}{|c|c|c|c|}
\hline & D227 & D228 & H. organivorans \\
\hline \multicolumn{4}{|l|}{ Morphological characteristics } \\
\hline Shape & Rod & Rod & Rod \\
\hline Size $(\mu \mathrm{m})$ & $0.5-0.7 \times 1.1-3.0$ & $0.5-0.8 \times 1.0-2.8$ & $1.0-1.2 \times 2.0-3.0$ \\
\hline Gram staining & - & - & - \\
\hline Mobility & + & + & + \\
\hline Spore formation & - & - & - \\
\hline \multicolumn{4}{|l|}{ Growth conditions } \\
\hline Optimum $\mathrm{NaCl}(\%, w / v)$ & $5-6$ & $5-6$ & $7.5-10$ \\
\hline Optimum temperature $\left({ }^{\circ} \mathrm{C}\right)$ & $30-35$ & $30-35$ & 37 \\
\hline Optimum pH & $6-7$ & $6-7$ & 7.0 \\
\hline Aerobic conditions & + & + & + \\
\hline \multicolumn{4}{|l|}{ Biochemical characteristics } \\
\hline Catalase & + & + & + \\
\hline Ornithine decarboxylase & - & - & - \\
\hline Arginine dihydrolase & - & - & NR \\
\hline Lysine decarboxylase & - & - & NR \\
\hline Urease & - & - & NR \\
\hline L-Arabitol & - & - & NR \\
\hline Galacturonate & - & - & + \\
\hline 5-Ketogluconate & + & + & NR \\
\hline Lipase & - & - & NR \\
\hline Phenol red & - & - & NR \\
\hline Beta-glucosidase & + & + & NR \\
\hline D-Mannitol & + & + & + \\
\hline D-Maltose & + & + & - \\
\hline Adonitol & + & + & - \\
\hline Palatinose & + & + & NR \\
\hline Beta-glucuronidase & - & - & NR \\
\hline Manonate & - & - & NR \\
\hline Indole formation & + & + & - \\
\hline N-Acetyl-beta-glucosaminidase & - & - & NR \\
\hline Beta-galactosidase & + & + & NR \\
\hline D-Glucose & + & + & + \\
\hline Sucrose & + & + & + \\
\hline L-Arabinose & + & + & - \\
\hline D-Arabitol & + & + & + \\
\hline Alpha-glucosidase & + & + & NR \\
\hline
\end{tabular}

mangroves, seas, and saline lakes. Furthermore, Halomonas spp. are moderate halophiles, requiring salt concentrations between 3 and 15\% (w/v) for growth (Mata et al. 2002; Gasperotti et al. 2018). Several Halomonas strains have been considered as ideal candidates for potential biotechnological applications, including degradation of organic pollutants and production of compatible solutes, biopolymer, and enzymes (Margesin and Schinner 2001).

In the present study, the $16 \mathrm{~S}$ rDNA sequences of the two selected strains were $99.4 \%$ similar to that of $H$. organivorans (Fig. 1), with only some phenotypic differences (Table 2).
Halomonas organivorans is a moderately halophilic bacterium that has been isolated from hypersaline habitats in southern Spain. This strain could utilize a wide range of organic compounds, such as benzoic acid, $p$-hydroxybenzoic acid, phenol, salicylic acid, cinnamic acid, and phenylpropionic acid, and can be employed for the decontamination of polluted saline habitats (García et al. 2004). However, there are no reports on the production of ectoine by $H$. organivorans, and the present study is the first to demonstrate ectoine accumulation in two $H$. organivorans strains from the Can Gio mangrove forest (Table 1). 

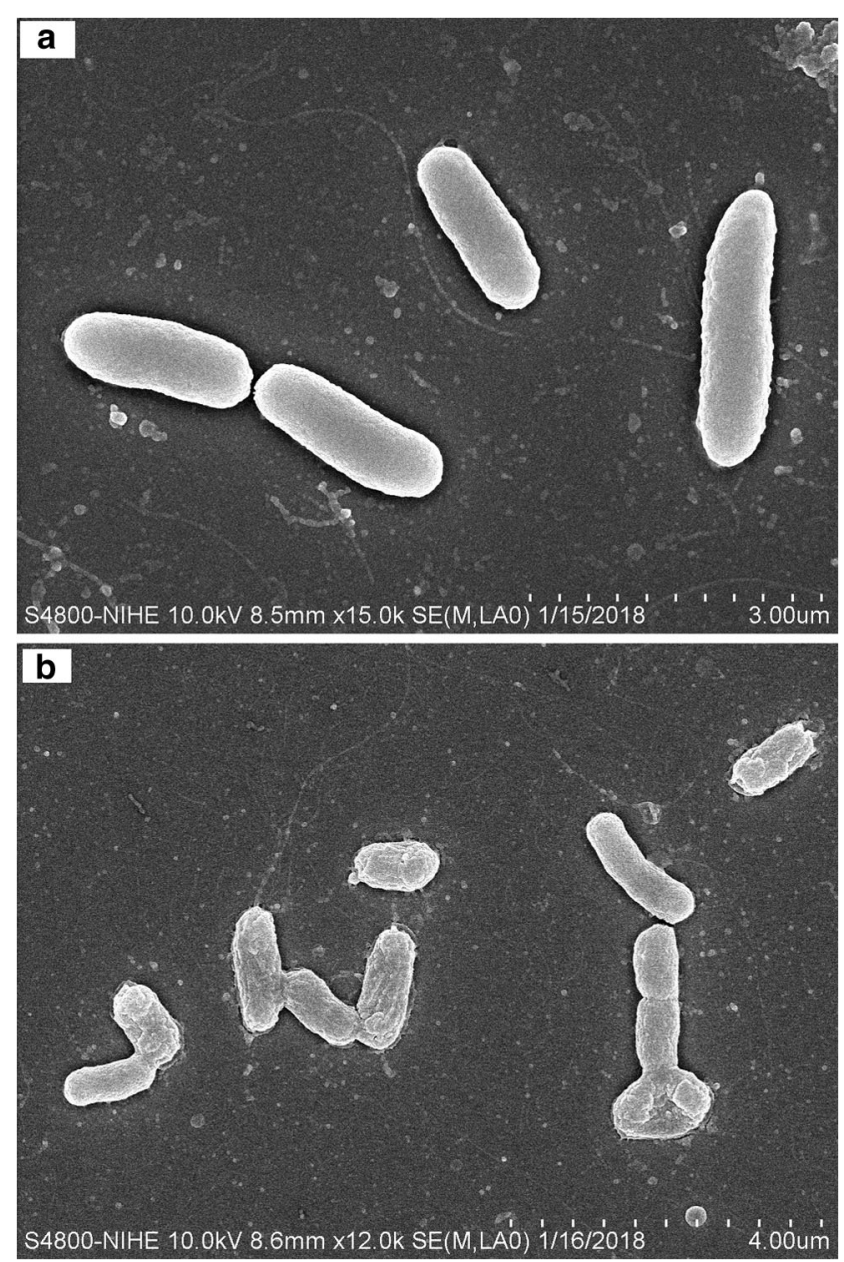

Fig. 2 Scanning electron micrographs of strains D227 (a) and D228 (b) showing their morphological features

Previous studies have established that the presence of $\mathrm{NaCl}$ is the key factor that significantly influences cell growth and ectoine accumulation of halophilic bacteria (Detkova and Boltyanskaya 2007; Van-Thuoc et al. 2010). With the main function of osmotic balance, the amount of ectoine in bacterial cells is

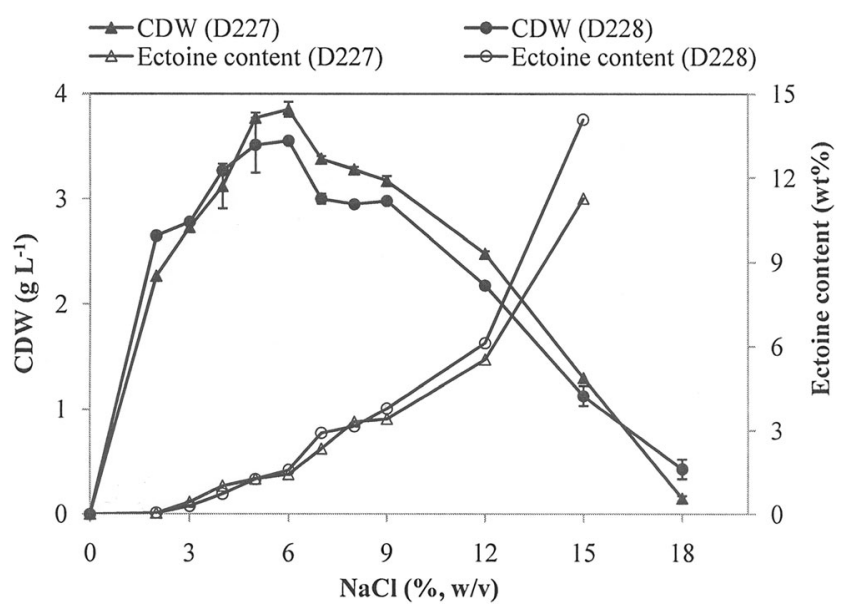

Fig. 3 Effect of $\mathrm{NaCl}$ concentration on cell growth and ectoine accumulation of the two selected strains
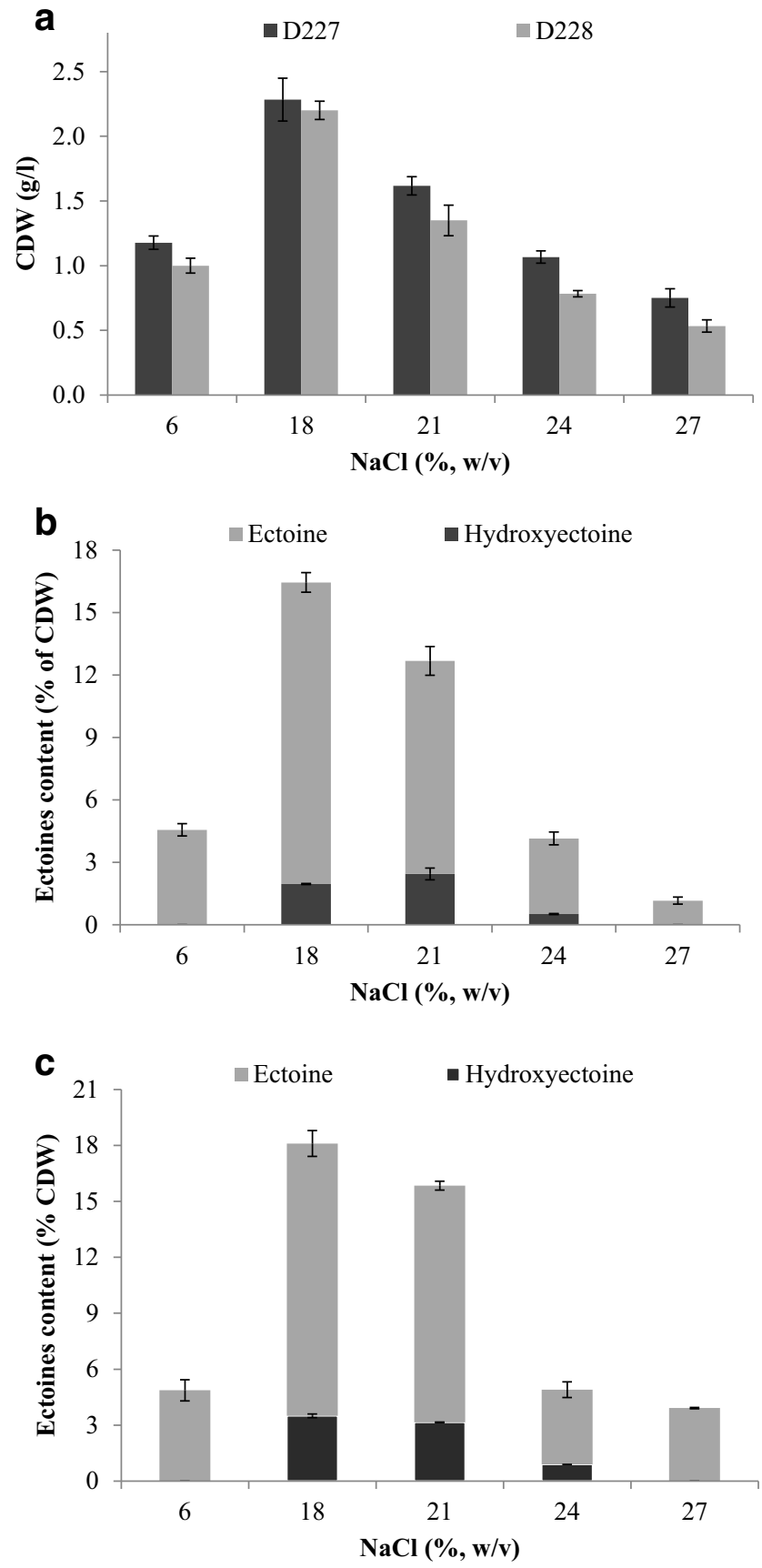

Fig. 4 Two-step fermentation for ectoine production by the two selected strains. The bacterial strains were first grown in MPA medium containing $6 \% \mathrm{NaCl}$, collected after $15 \mathrm{~h}$ of cultivation, and transferred to $\mathrm{HM}$ containing $18 \%, 21 \%, 24 \%$, and $27 \% \mathrm{NaCl}$. CDW (a), ectoines produced by strain D227 (b), and ectoines produced by strain D228 (c) at different salt concentrations

controlled by the concentration of $\mathrm{NaCl}$ in the culture medium. In the present study, the ectoine content produced by the two isolated strains increased and reached the maximum value when the $\mathrm{NaCl}$ concentration in the culture medium was increased to $18 \%$ (Fig. 4b, c). The total ectoine content generated by strain D227 (16.5 wt\%) and strain D228 (18.1 wt\%) is comparable to that produced by commercial ectoine producers such as $H$. elongata 

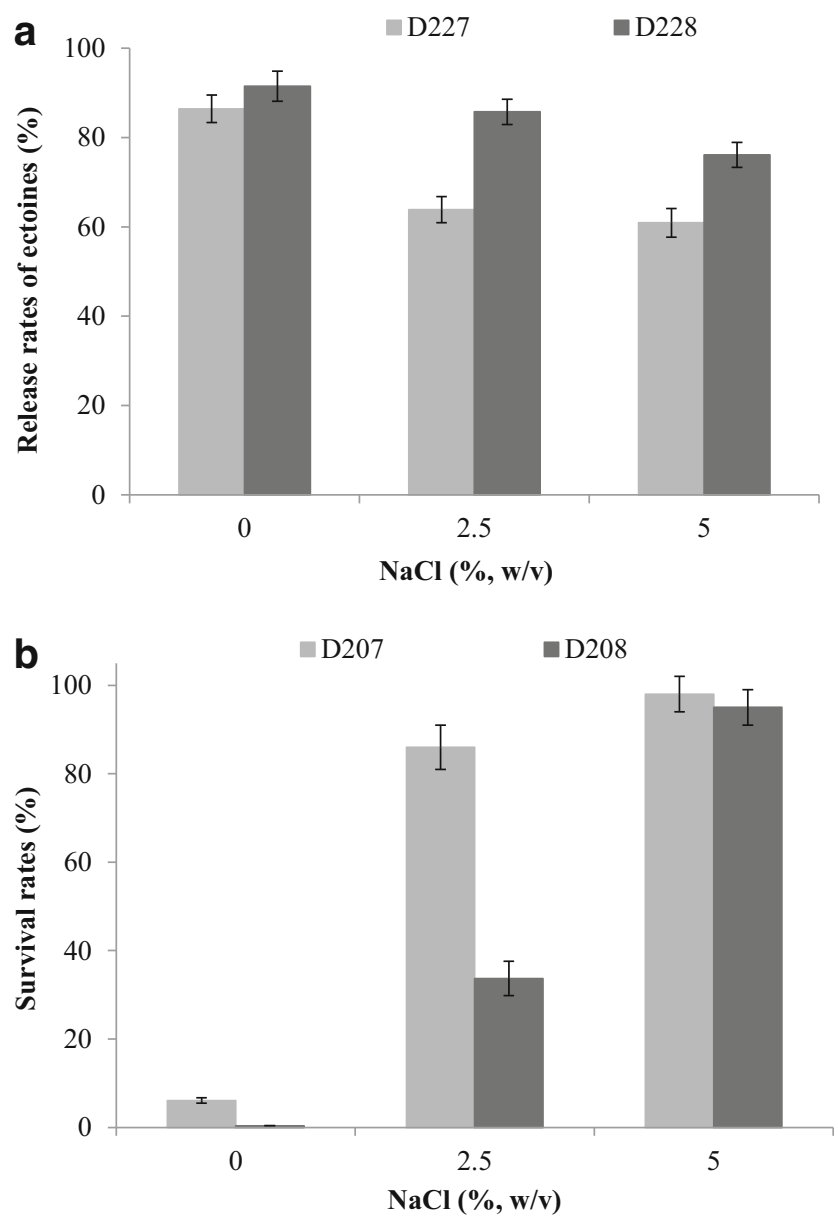

Fig. 5 Effect of $\mathrm{NaCl}$ concentration in the downshock solution on ectoine release rates (a) and survival rates (b) for the two selected strains

(15.5 wt\%) (Sauer and Galinski 1998). Besides, a small amount of hydroxyectoine was also detected in the two selected strains when the $\mathrm{NaCl}$ concentration in the culture medium was $18 \%$ or higher (Fig. 4b, c), similar to that noted in earlier studies on other Halomonas spp. (Van-Thuoc et al. 2010; Öztürk et al. 2015). Hydroxyectoine is a better stress protector than ectoine and has been shown to preserve various biological functions (Lippert and Galinski 1992; Borges et al. 2002; Van-Thuoc et al. 2013). Halophilic bacteria tend to produce hydroxyectoine under severe stress conditions (Guzmán et al. 2009; Öztürk et al. 2015). Interestingly, in the present study, although the optimum $\mathrm{NaCl}$ concentration for the growth of the two selected strains was 3$6 \%(w / v)$, both the strains could grow at $\mathrm{NaCl}$ concentration of up to $21 \%(w / v)$ owing to protection from compatible solutes (ectoine and hydroxyectoine). The concentration of ectoine and hydroxyectoine in the two selected bacterial strains changed with the amount of $\mathrm{NaCl}$ in the culture medium, which is an important feature that helps the bacteria to adapt and survive under different environmental conditions. However, ectoine and hydroxyectoine could only help to protect the bacterial cells at certain concentrations of $\mathrm{NaCl}$; the two selected strains were inhibited and destroyed when the $\mathrm{NaCl}$ concentration in the culture medium was higher than $21 \%$ (Fig. $4 a$ ).

Besides $\mathrm{NaCl}$ concentration, medium composition was also found to be an important factor affecting ectoine accumulation. At similar temperature and $\mathrm{NaCl}$ concentration, the MPA medium was noted to stimulate lower ectoine production than modified HM. Strains D227 and D228 produced 9.1 and $9.9 \mathrm{wt} \%$ ectoine, respectively, after $30 \mathrm{~h}$ of cultivation in MPA medium containing $15 \% \mathrm{NaCl}$ (Table 1); in contrast, the ectoine content increased to 12.3 and $14.1 \mathrm{wt} \%$, respectively, after $30 \mathrm{~h}$ of cultivation when HM containing the same concentration of $\mathrm{NaCl}$ was employed (Fig. 3). In general, halophilic and halotolerant organisms use a group of solutes (cocktails of solutes), and not just a single solute, for osmotic balance (Roberts 2005). The modified HM is a defined medium, while MPA is a complex medium containing precursors for various solutes. Thus, with the availability of these precursors in the culture medium, the bacterial cells tend to synthesize several molecules that together contribute to osmotic balance. Therefore, in addition to the salt concentration in the culture medium, regulation of the amount of precursors for ectoine and other compatible solutes in the culture medium is another approach to control ectoine accumulation in bacterial cells.

It is important to note that the ideal ectoine-producing strain must efficiently release the intracellularly accumulated ectoines when subjected to hypoosmotic shock and survive and resynthesize the osmolytes after downshock. Previous studies have demonstrated that the ectoine release rates and bacterial survival rates are controlled by the $\mathrm{NaCl}$ concentration in the downshock solution (Nagata et al. 2008; VanThuoc et al. 2013). While the lowest bacterial survival rates and highest ectoine release rates could be achieved by suspending bacterial cells in distilled water, an increase in the $\mathrm{NaCl}$ concentration in the downshock solution could lead to a decrease in ectoine release rates and an increase in bacterial survival rates (Nagata et al. 2008; Van-Thuoc et al. 2013). Similar result was also noted in the present study, with about $90 \%$ of accumulated ectoines released by the two bacterial strains in distilled water, whereas the release rates decreased when the $\mathrm{NaCl}$ concentration was increased to $2.5 \%$ and $5 \%$ (Fig. 5a). However, excess secretion of accumulated ectoines to the surrounding medium resulted in a decrease in the bacterial survival rates, with only $6 \%$ of strain D227 and less than $1 \%$ of strain 228 surviving after $30 \mathrm{~min}$ of incubation in distilled water (Fig. 5 b). In contrast, the viability of cells increased in the presence of $2.5 \%$ and $5 \% \mathrm{NaCl}$. These results are comparable with those obtained with commercial strain (H. elongata). For instance, the ectoine release rates for strains D227 and D228 were $61 \%$ and $76 \%$, respectively, while the 
bacterial survival rates for the two strains were $98 \%$ and $96 \%$, respectively, after $30 \mathrm{~min}$ of incubation in the presence of $5 \%$ $\mathrm{NaCl}$. Meanwhile, the ectoine release rate and bacterial survival rate for the commercial strain $H$. elongata have been reported to be $64 \%$ and $86 \%$, respectively, in the presence of $3 \% \mathrm{NaCl}$ (Sauer and Galinski 1998).

In conclusion, the present study demonstrated that the two bacterial strains isolated from Can Gio mangrove soil can be promising candidates for commercial ectoine production. Both the strains were able to synthesize high contents of ectoine, rapidly release accumulated ectoine, and maintain high survival rates after being subjected to hypoosmotic shock. Currently, studies on the optimization of the culture medium for ectoine production using the two isolated strains are in progress.

Funding This research was supported by the Ministry of Education and Training (Grant B2007-SHP-32) and Vietnam National Foundation for Science and Technology Development (Nafosted) (Grant 106-NN.04-2016.11).

\section{Compliance with ethical standards}

Conflict of interest The authors declare that they have no conflict of interest.

Research involving human participants and/or animals This article does not contain any studies with human participants or animals performed by any of the authors.

\section{References}

Borges N, Ramos A, Raven NDH, Sharp RJ (2002) Comparative study of the thermostabilizing properties of mannosylglycerate and other compatible solutes on model enzymes. Extremophiles 6:209-216

Bünger J, Driller H (2004) Ectoine: an effective natural substance to prevent UVA-induced premature photoaging. Skin Pharmacol Physiol 17:232-237

Costa-Böddeker S, Thuyen LX, Schwarz A, Huy HD (2017) Diatom assemblages in surface sediments along nutrient and salinity gradients of Thi Vai estuary and Can Gio mangrove forest, Southern Vietnam. Estuar Coast 40:479-492

Detkova EN, Boltyanskaya YV (2007) Osmoadaptation of haloalkaliphilic bacteria: role of osmoregulators and their possible practical application. Microbiology 76:511-522

García MT, Mellado E, Ostos JC, Ventosa A (2004) Halomonas organivorans sp. nov., a moderate halophile able to degrade aromatic compounds. Int J Syst Evol Microbiol 54:1723-1728

Gasperotti AF, Revuelta MV, Studdert CA, Seitz MKH (2018) Identification of two different chemosensory pathways in representatives of the genus Halomonas. BMC Genomics 19:266

Guzmán H, Van-Thuoc D, Martín J, Hatti-Kaul R (2009) A process for the production of ectoine and poly(3-hydroxybutyrate) by Halomonas boliviensis. Appl Microbiol Biotechnol 84:1069-1077

Holguin G, Vazquez P, Bashan Y (2001) The role of sediment microorganisms in the productivity, conservation, and rehabilitation of mangrove ecosystems: an overview. Biol Fertil Soils 33:265-278
Kanapathipillai M, Lentzen G, Sierks M, Park CB (2004) Ectoine and hydroxyectoine inhibit aggregation and neurotoxicity of Alzheimer's $\beta$-amyloid. FEBS Lett 579:4775-4780

Kunte HJ, Galinski EA, Trüper HG (1993) A modified FMOC-method for the detection of aminoacid type osmolytes and tetrahydropyrimidines (ectoines). J Microbiol Methods 17:129-136

Kunte HJ, Lentzen G, Galinski EA (2014) Industrial production of the cell protectant ectoine: production mechanisms, processes, and products. Curr Biotechnol 3:10-25

Lentzen G, Schwarz T (2006) Extremolytes: natural compounds from extremophiles for versatile applications. Appl Microbiol Biotechnol 72:623-634

Lippert G, Galinski EA (1992) Enzyme stabilization by ectoine-type compatible solutes: protection against heating, freezing and drying. Appl Microbiol Biotechnol 37:61-65

Malin G, Lapidot A (1996) Induction of synthesis of tetrahydropyrimidine derivatives in Streptomyces strains and their effect on Escherichia coli in response to osmotic and heat stress. J Bacteriol 178:385-395

Margesin R, Schinner F (2001) Potential of halotolerant and halophilic microorganisms for biotechnology. Extremophiles 5:73-83

Mata JA, Martínez-Cánovas J, Quesada E, Béjar V (2002) A detailed phenotypic characterization of the type strains of Halomonas species. Syst Appl Microbiol 25:360-375

Moh TH, Lau N-S, Furusawa G, Amirul A-AA (2017) Complete genome sequence of Microbulbifer $\mathrm{sp.} \mathrm{CCB-MM1,} \mathrm{a} \mathrm{halophile} \mathrm{isolated} \mathrm{from}$ Matang mangrove forest, Malaysia. Stand Genomic Sci 12:36

Nagata S, Wang Y, Oshima A, Zhang L, Miyake H, Sasaki H, Ishida A (2008) Efficient cyclic system to yield ectoine using Brevibacterium sp. JCM 6894 subjected to osmotic downshock. Biotechnol Bioeng 99:941-948

Onraedt AE, Walcarius BA, Soetaert WK, Vandamme EJ (2005) Optimization of ectoine synthesis through fed-batch fermentation of Brevibacterium epidermis. Biotechnol Prog 21:1206-1212

Öztürk HU, Sariyar Akbulut B, Ayan B, Poli A (2015) Moderately halophilic bacterium Halomonas sp. AAD12: a promising candidate as a hydroxyectoine producer. J Microb Biochem Technol 7:262-268

Pastor JM, Salvador M, Argandoña M, Bernal V (2010) Ectoines in cell stress protection: uses and biotechnological production. Biotechnol Adv 28:782-801

Roberts MF (2005) Organic compatible solutes of halotolerant and halophilic microorganism. Saline Syst (On-line Journal) 1:5

Sam K-K, Lau N-S, Furusawa G, Amirul A-AA (2018) Draft genome sequence of halophilic Hahella sp. strain CCB-MM4, isolated from Matang mangrove forests in Perak, Malaysia. Genome Announc 5: e01147-e01117

Sauer T, Galinski EA (1998) Bacterial milking: a novel bioprocess for production of compatible solutes. Biotechnol Bioeng 57:306-313

Schröter MA, Meyer S, Hahn MB, Solomun T, Sturm H, Kunte HJ (2017) Ectoine protects DNA from damage by ionizing radiation. Sci Rep 7:15272

Ser H-L, Tan W-S, Mutalib N-SA, Yin W-F (2018) Genome sequence of Streptomyces mangrovisoli MUSC 149T isolated from intertidal sediments. Braz J Microbiol 49:13-15

Tamura K, Stecher G, Peterson D, Filipski A (2013) MEGA6: molecular evolutionary genetics analysis version 6.0. Mol Bio Evol 30:2725-2729

Tuan VQ, Kuenzer C (2012) Can Gio mangrove biosphere reserve evaluation 2012: current status, dynamics and ecosystem services, IUCN, Hanoi, Vietnam 102 pp

Van-Thuoc D, Guzmán H, Quillaguamán J, Hatti-Kaul R (2010) High productivity of ectoines by Halomonas boliviensis using a combined twostep fed-batch culture and milking process. J Biotechnol 147:46-51

Van-Thuoc D, Huu-Phong T, Thi-Binh N, Thi-Tho N, Minh-Lam D, Quillaguamán J (2012) Polyester production by halophilic and 
halotolerant bacterial strains obtained from mangrove soil samples located in northern Vietnam. MicrobiologyOpen 1:395-406

Van-Thuoc D, Hashim SO, Hatti-Kaul R, Mamo G (2013) Ectoine mediated protection of enzyme from the effect of $\mathrm{pH}$ and temperature stress: a study using Bacillus halodurans xylanase as a model. Appl Microbiol Biotechnol 97:6271-6278

Werkhäuser N, Bilstein A, Sonnemann U (2014) Treatment of allergic rhinitis with ectoine containing nasal spray and eye drops in comparison with azelastine containing nasal spray and eye drops or with cromoglycic acid containing nasal spray. J Allergy:176597

Zhang LH, Lang YJ, Nagata S (2009) Efficient production of ectoine using ectoine-excreting strain. Extremophiles 13:717-724

Publisher's note Springer Nature remains neutral with regard to jurisdictional claims in published maps and institutional affiliations. 